\title{
Neueinstellungen + Mutationsmeldungen für angestellte Therapeuten
}

Neueinstellungen, Austritte und Änderungen der Personaldaten angestellter Therapeuten sind auf diesem Formular anzugeben und mit den erforderlichen Beilagen zu senden an:

santésuisse, Frau M. Berthel, Römerstrasse 20, 4502 Solothurn

\section{Arbeitgeber}

Zahlstellennummer:

Name:

Vorname:

Praxisadresse, PLZ/Ort:

\section{Arbeitnehmer}

\section{Neueinstellung}

Name:

Vorname:

Geburtsdatum: angestellt $a b$ :

Ausbildungsland: Diplomjahr

Fachausbildung als:

Fachausbildung als:

Fachausbildung als:

Fachausbildung als:

Fachausbildung als:

* SRK Schweizerisches Rotes Kreuz

${ }^{* *}$ SBK Schweiz. Berufsverband der Pflegefachfrauen und Pflegefachmänner

\section{Austritt}

$\mathrm{K}-\mathrm{Nr}$.

Name:

Vorname:

Geburtsdatum:

Austritt per

\section{Änderung der Personalangaben bisheriger Mitarbeiter/innen:}

\section{$\mathrm{K}-\mathrm{Nr}$.}

Name: Vorname:

Geburtsdatum:

Änderung: per:

PS: Für allfällige Rückfragen steht Ihnen Frau M. Berthel gerne zur Verfügung (Dienstag und Freitag von 8.30 bis 11.00 Uhr, Tel. 03263916 61, Fax 03263916 78, E-Mail: marion.berthel@santesuisse.ch). 